Urszula Soczyniska

\title{
PHYSICO-GEOGRAPHICAL PRINCIPLES OF MODELLING THE DYNAMIC HYDROLOGICAL SYSTEMS
}

\section{ANALYSIS OF THE HYDROLOGICAL SYSTEM}

The catchment area is a fundamental research unit in hydrology. Careful examination and understanding of the hydrological role of a basin requires to consider it as a complex dynamic system, its oojects being in mutual functional relationship. This kind of the dynamic system has been known for a long time as a basin hydrological cycle. Figure 1 presents the block diagram of a basin representing relationship of the water cycle components. In the simplest approach, a hydrological cycle may be characterized as an input to the system in the form of atmospheric precipitation and potential evaporation, which, being distributed into different kinds of storages, tends in effect to the output in form of outflow in a river cross-section, deep ground outflow and land evaporation. Considering the water cycle elements as time dependent, the hydrological cycle can be expressed in the form of a simple, dynamic water balance equation

$P(t)=Q(t)+Q A(t)+E V A P(t)+\lambda(\mathrm{LNT}, \mathrm{RPP}, \mathrm{RPN}, \mathrm{RSA}, \mathrm{RWG}, \mathrm{RA}, \mathrm{RKR})$

Symbols in the equation are explained in the scheme (Fig. 1).

For better clarity, the scheme has been divided into five subsystems representing isolated water cycle phases (plant canopy, basin surface, unsaturated zone, ground water and river channels).

Input to the system consists of precipitation $(P)$ and potential evaporation (EPOT), governing the intensity of different forms of land evaporation (EVAP). The rainfall reaches directly and simultaneously the three basin subsystems, feeding its storages (river-bed, interception and surface storage). Plant canopy interception storage (INT) is fed by rainfall only. Part of the water evaporates to the atmosphere (EPR), and the other part, exceeding the upper limit of its capacity in the form of dropping (OC), feeds two storages of the basin surface subsystem: stor- 


\section{SCHEME OF WATER CYCLE IN A BASIN AREA}

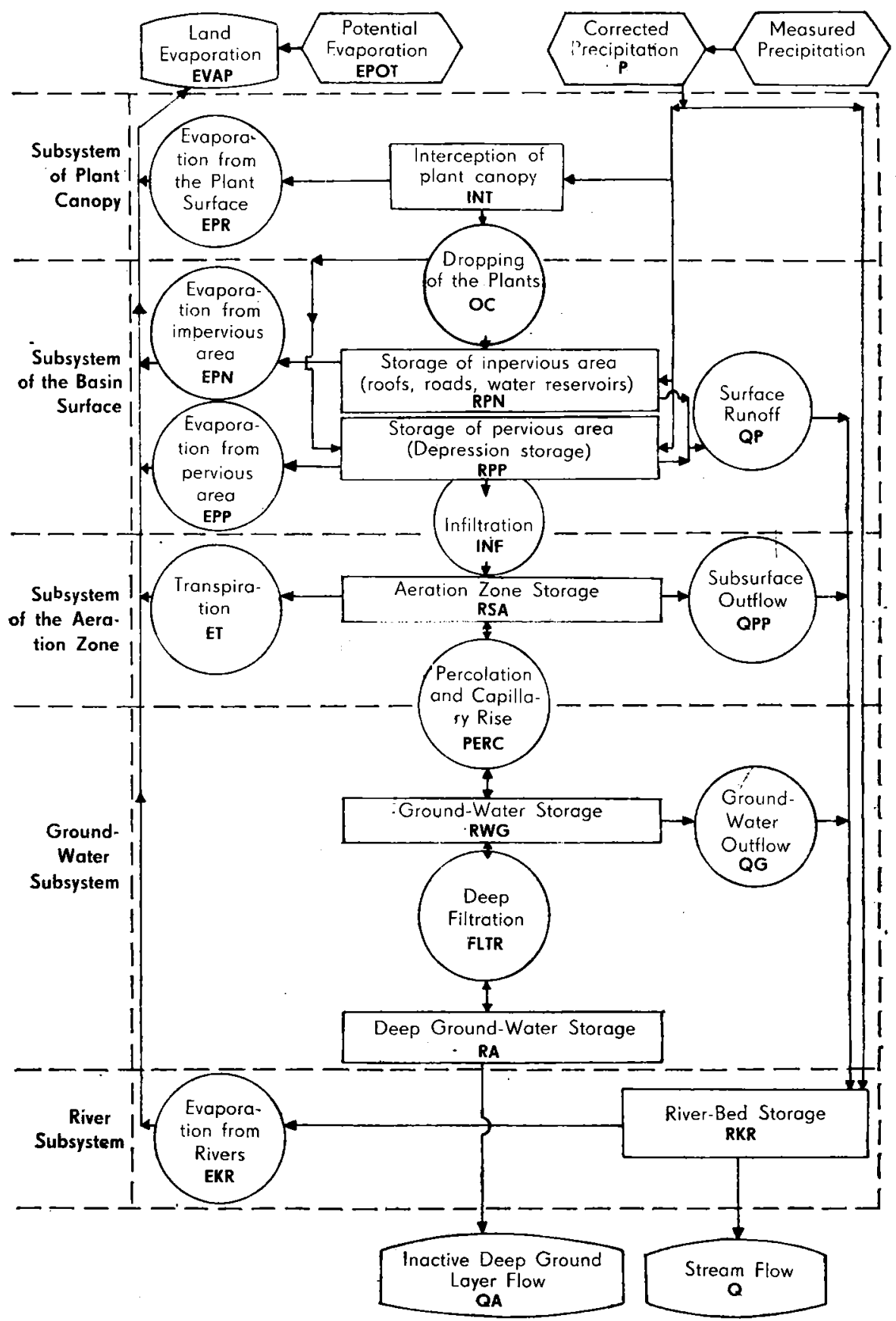

Fig. 1. Scheme of water cycle in a basin area 
age of impermeable (RPN) and permeable surface (RPP). Thus, input to RPN storage consists of rainfall and dropping of plants and output of evaporation (EPN) and surface outflow (QP). Storage RPP is fed similarly as RPN, and emptied by evaporation (EPP), infiltration (INF) and surface outflow (QP), initiated after filling the unsaturated zone storage (RSA). Infiltration is a process of water exchange between the surface and subsurface basin subsystems.

The unsaturated zone storage (RSA), fed by rainfall infiltration (INF) is emptied by plant transpiration (ET), percolation to the saturation zone (PERC) and the subsurface flow (QPP). It should be stressed that the emptying of the RS0 storage in the form of percolation to ground water storage (RWG) during the intensive rainfalls and during droughts, may change the direction of feeding (there appears the capillary rise process). Ground water storage (RWG), fed by percolation (PERC), is emptied by ground water outflow (QG) and partly and periodically by capillary rise as well as by filtration (FLTR) to deep ground-water layers having no contact with the stream draining the basin (inactive deep ground-water storage - RA). The emptying of this storage occurs periodically by exfiltration to ground water storage as well as by outflow to adjacent river basins. At last the river-bed storage (RKR), fed directly by rainfall and three kinds of outflows (QP, QPP, QG) is then emptied by streamflow (Q) as well as by direct evaporation from river surfaces (EKR).

The presented block-scheme of the dynamic hydrologic system and the analysis of its components represent the general picture of water cycle in a basin area during the vegetation season, just after the heavy rainfall occurrence. In the case of winter season the structure of the system gets more complicated because of the necessity of adding the snow-melt subsystem, containing the processes of moisture and heat exchange between the snow-pack, atmosphere and soil surface. An additional complication is the requirement of complementing the scheme with the soil freezing subsystem, aimed at controlling the infiltration in the period of negative air temperatures occurrence.

\section{POSSIBILITIES OF MODELLING THE HYDROLOGICAL PROCESSES}

Up to now, a large number of mathematical models have been worked out in various countries of the world. These are models of separate processes, of basin components, integral and global models, black and gray box models, deterministic and probabilistic ones, lumped and distributed, time variant and invariant... and many others.

However, from the point of view of parameter identification methods, they may be divided into two main groups: 
- conceptual models

- physico-mathematical models.

The conceptual models represent the logical system of the mutual relations and iriteracting of the hydrological processes occurring in a basin. The structure of the conceptual model consists, in general, of the transformation functions described with empirical or semi-empirical equations. Parameters of these models have no physical sense, so in consequence, they cannot be measured directly in a field or found out from maps. For these reasons, there is a necessity of their estimation by optimization procedures. What does it mean? This means, that their estimation requires long realization of input and output data. These models have been for years used satisfactorily for forecasting purposes or simulating outflows in gauged basins.

However, we are not always in the possession of sufficiently long realizations of input and output elements. In watershed models, the input, is an atmospheric hietograph. The output of the model is an outflow hydrograph in the closing cross-section. If the profile is not controlled, the identification of the conceptual model in such a basin will not be practically possible. There is, however, a: possibility of working out the regression relations between the vector of model parameters and the one of a basin characteristics, which could be a basis for the model extrapolation to the ungauged basins. However, in the case of complex models with a large number of parameters, this method may be very difficult and it does not promise good results.

Considering the difficulties in estimating the parameters by optimization procedures in many practical cases, the research efforts should be aimed at application in practice of integral physically based models.

This type of a model should meet the following conditions:

- all important water cycle processes in a basin should be described by separate operators,

- the transformation functions of the operators as well as their parameters should have the physical meaning,

- identification of the model parameters should be accomplished by their direct measurement in a basin area or by the establishment of their relationships with other characteristics of a basin,

- account should be taken of time-variability as well as of space distribution of processes operators and their parameters.

Description of hydrological processes with mathematical physics equations imposes à priori the set of parameters, which are not a set of ordinary numerical coefficients, but have a univocal physicai meaning. Theoretically it should be possible to establish them directly in 


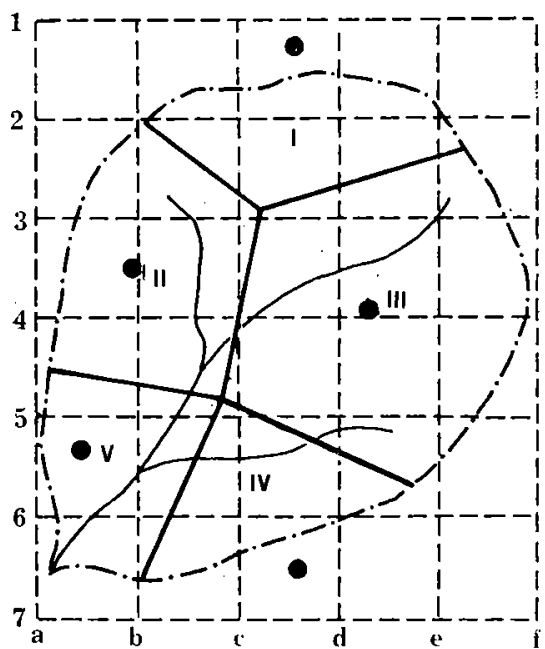

a

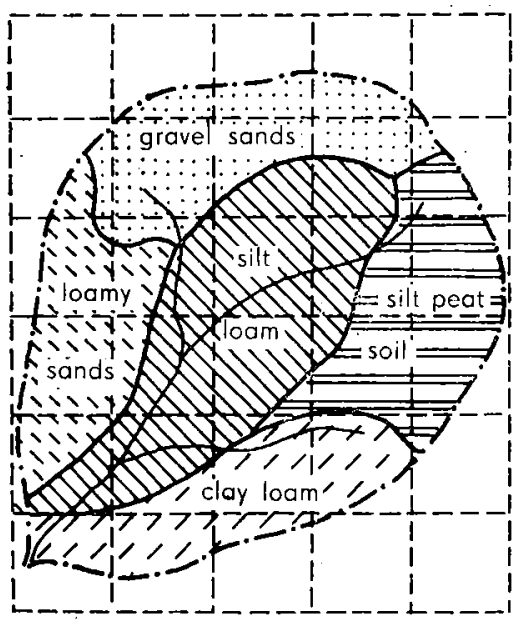

C

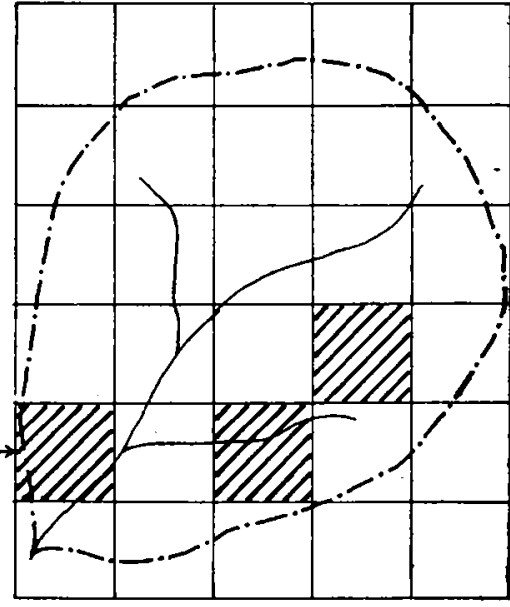

- one set of parameters

d

Fig. 2. Conception of distinguishing of the unit quasi-homogenous areas a) areas of equal rain depths in a basin

b) quasi-homogenous areas of plant canopy in a basin (interception and land evaporation process)

c) quasi-homogenous areas of soils in a basin (land evaporation and infiltration process)

d) geometric square grid. 
a field. Due to a space distribution of the parameters, it is necessary to divide a basin into unit sub-areas, resulting from the requirement of each process. Every separtated unit has to result from natural, physico-geographical features of the basin area and should represent one set of parameters iwithin each process.

Because of the necessity of the application of electronic computational technics, the basin area must be covered with an auxiliary geometric grid, in the nodes (or centres) of which the values of parameters will be established. The discrete space parameter distribution achieved in this way gives the possibility of water movement description in every grid node (or centre), or, speaking more precisely, in the area subordinated to it in the form of the one-dimensional lumped model.

The space step of the grid depends on the physico-geographical differentiation of a basin, its size as well as the time-interval of computations.

Figure 2 presents the conception of distinguishing the unit quasihomogenous areas and of determination of parameters in square grid areas. In case of the existence of several rainfall posts within a basin (Fig. 2a), we divide its area into subareas of equal rain depths (by one of the accepted methods). Putting then the square grid on the basin map, we can determine in its areas the depths of rainfall in particular time intervals $\Delta t$. In areas situated on the border of two or three subareas, the rain depth is calculated by the mean weighted method. Figure $2 \mathrm{~b}$ illustrates the distinguishing of the unit areas with similar type of plant cover. The details of the division depend upon the possibility of differentiation of maximum interception storage (INT $\max$ ) for different kinds of plant canopy (Gutry-Korycka, 1980). The division of the basin according to different soil types is shown in Figure 2c. It is a basis for identification of the hydrological soil parameters $(p F(\Theta)$ retention curves and hydraulic conductivity coefficients $k(\Theta)$, indispensable for the description of the infiltration process (Soczyńska, Gutry-Korycka, Jaworski, 1982). The last two maps are also a basis for determination of parameters in land evaporation model (Jaworski, 1980). All parameter values in centres of the square grid are estimated by the mean weighted method (Fig. 2d), obtaining in each square area the set of parameters indispensable to describe hydrological processes occurring in surface and subsurface zone of the basin. The description of overland flow requires also the distinguishing of the non-drainage areas and carrying off the geometrization of the basin area by replacement of the natural slopes and stream network by the set of channels and rectangular planes.

The purpase of research undertaken in Poland has been the working 
out of the basin integral model which in future could be utilized for hydrologic processes simultation in basins of insufficient hydrological control as well as for investigation of the impact of human activity on quantitative changes of water circulation elements.

Research has been conducted since 1978 in the experimental basin of the upper Wilga River. The basin has the area equal to $250 \mathrm{~km}^{2}$ and is considered as a representative one of the Middle Polish Lowland.

\section{CONCLUSIONS}

The present state of development of the theoretical methods should be evaluated positively. In principle, every process can be described theoretically. On the other hand, the problem of determining the parameters directly in the field is always fraught with difficulties and constitutes a serious restraint for practical application of physically based models. The problem should be considered as one of the most difficult in the mathematical modelling of a basin behaviour. For this reason, most attention should be devoted to the problem of identifying the parameters.

Physical parameters of a basin, constituting an integral part of the basin model structure (or individual component process) can be divided into two basic groups:

1. the parameters closely connected with the studied basin area (e.g. slopes, length of slopes and of river bed segments, geometry of river bed, depth of aeration zone, capacity of depression storage, and so on),

2. the parameters not connected with a given basin but representing various physical environments (e.g. interception capacity of plant canopy, soil water characteristic curves, roughness coefficients as well as a large number of parameters representing snow-melt processes, land evaporation and so on).

Results obtained and accumulation of a large number of information on the values of parameters permit the undertaking of works on organizing a bank of parameters. The bank will contain the numerical values of parameters according to the specificity of the physico-geographical environment as well as to hydrological season.

In our opinion this is the only way to the effective breaking up the barrier setting back the practical application of physically based models in natural catchment areas. 


\section{REFERENCES}

Gutry-Korycka, M., "Matematyczno-fizyczne aspekty procesu intercepcji szaty roślinnej" (Physical and Mathematical Aspects of Plant Canopy Interception Process), Przeglad Geograficzny, No. 2, 1980.

J a w orski, J., "Podstawy metodyczne wyznaczania ewapotranspiracji aktualnej" (Methodological Foundations of Designation of Actual Evaporation), Materiaty Badawcze Instytutu Meteorologii i Gospodarki Wodnej, Warszawa 1980. Soczyńska U., Gutry-Korycka, M., Jaworski, J., "Determination of a Basin Physical Parameters for Mathematical Modelling of Hydrological Processes", Journal of Hydrological Sciences, No. 1-4, 1982. 